\title{
Review of Post-Harvest Losses of Fruits and Vegetables
}

\author{
Yahaya SM* and Mardiyya AY \\ Department of Biology, Nigeria
}

Received: 㑘 January 19, 2019; Published: 眥 January 28, 2019

*Corresponding author: Yahaya SM, Department of Biology, Kano University of Science and Technology, Wudil, Nigeria

\begin{abstract}
Fruits and vegetables are among the most perishable agricultural cultivated in Nigeria, especially the Northern part of the country. However, poor handling method has resulted in to a serious post-harvest loss of these agricultural produce in addition to loss of time and money spend. Therefore, in most cases farmers suffer a huge economic loss due to lack of proper understanding about nature and causes of these loss, proper preservation methods and their transportation and marketing techniques. However, this may be reduced tremendously, by using adequate cultural methods, such as careful handling and packaging. Furthermore, the use of appropriate chemicals during pre and post-harvest stage may sometimes extend the shelf life of the produce and make it available over a long period time by protecting the fruit and vegetables from attacked of pathogens and other environmental damage. Consequently, this review suggests the procedure of handling the fruits and vegetables after their harvest so as to reduce the loss and maximizing the returns from them which may result in increased availability and reduce cost of the commodity.
\end{abstract}

Keywords: Fruits; Vegetables; Postharvest; Control

\section{Introduction}

Fruits and vegetables are very important food commodities not only in developing country like Nigeria but all over the world. Nigeria, which is the most densely populated country in African continent, is still struggling to achieve self-sufficiency to feed about 150 million people. For this purpose, fruits and vegetables have got their specific importance to provide a balance and healthy diet to the people [1]. Alao, [2] observed that practically all fresh vegetables grown in Nigeria are consumed in Nigeria and Production is seasonal resulting in a glut during the season and scarcity at off seasons. Due to their soft texture they are easily bruised or wounded as a result of harvesting, and other post-harvest handling operation such as packaging, transportation and storage. In Northern part of Nigeria, despite producing adequate quantities of fruits and vegetables, yet on account of losses in the field as well as in storage, they become inadequate. Mustapha and Yahaya [3] reported that the complex and long chain of marketing system of vegetables between the farmers and consumers makes it difficult to assess the level of damage in many crops in Nigeria. However, generally, about $30 \%$ fruits and vegetables are rendered unfit for consumption due to spoilage after harvesting. This is a huge loss of valuable food even when the minimum food requirement of the population is not met. In 1989, FAO report indicated that Nigerian vegetables have not been able to meet world standard because of poor harvest handling. Therefore, it is important not only to grow more, but also to save what is grown at high cost $[2,4]$.
Alao [2] defined Post harvest loss of fruits and vegetables as "that weight of wholesome edible product (exclusive of moisture content) that is normally consumed by human and that has been separated from the medium and sites of its immediate growth and production by deliberate human action with the intention of using it for human feeding but which for any reasons fails to be consumed by human." Not only quantity and quality but even the appearance of fruits and vegetables are affected, and their market value is reduced [5]. Most 'skin deep' injuries such as 'fly speck' in apples do not affect the edible part. Some infections are not harmful as they occur on inedible parts and can be trimmed off before consumption ego Alternaria spots on the outer leaves of cabbage [6]. Fresh fruits and vegetables are perishable and highly prone to these losses because they are composed of living tissues. These tissues must be kept alive and health throughout the process of marketing. These are composed of thousands of living cells which require care and maintenance $[2,3]$.

Therefore, the reduction of post-harvest loss of fruit and vegetables is a complementary means for increasing production. It may not be necessary to considerably step up the production of fruits and vegetables with the growing demand if the post-harvest loss is reduced to a great extent. The cost of preventing losses after harvest in general is less than preventing a similar additional amount of fruit and vegetable crop of the same quality. Attention 
to the concept of post-harvest food loss reduction, as a significant means to increase food availability, was drawn by the World Food Conference held in Rome in 1987.

\section{Factors affecting Post-Harvest Loss}

In general, post-harvest losses of fruits and vegetables is influence by many factors. These factors includes losses due to physical, physiological, mechanical and hygienic conditions. Fruits and vegetables are mainly characterized by high level metabolic activities and known to posse's short shelf life. As a result of these factors, substantial percentage of loss occurs between harvesting to consumption of the produce $[7,8]$. In addition, other factors such as insect and mite injury, diseases which occur due to non-infectious pathogens and pathological rots also cause post-harvest loss of fruits and vegetables. However, among the causes, the pathological rots are the most serious which is followed by mechanical injury. Pathological rots in combination with mechanical damage cause serious damage to the perishables [3,9]. Environmental factors such as temperature, relative humidity and oxygen balance most especially during storage are also greatly responsible for damage also environmental conditions such as temperature and humidity are responsible for rendering fruits and vegetables susceptible for pathological attacks. However, the loss of fruits and vegetables due to physiological and biochemical damage are closely interrelated $[8,10]$. Therefore, post-harvest loss of fruits and vegetables can be studied as primary and secondary causes.

Primary causes of Post-Harvest Loss of Fruits and Vegetables: The primary factors of post-harvest loss of fruits and vegetables are mainly cause by mechanical physiological pathological or environmental factors [11].

\section{Mechanical Injury}

Mechanical damage of fruits and vegetables are caused by careless handling during harvesting, packing, transportation, storage etc. Some insects and birds are also responsible for the mechanical injury in fruits and vegetables $[2,7,11]$. In many cases damage cause by mechanical injuries like bruising and cracking of fruits and vegetables render them more prone to attack by organisms and this increase the rate of water loss and gaseous exchange. Several tines the damage cause by mechanical injury on fruits and vegetables as a result of pressure thrust during transportation, though many times invisible, but causes rupturing of inner tissues and cells. Such produce is degraded faster during the natural ageing process $[2,11]$.

The possibility that fruits and vegetables encountering maximum mechanical damage during harvesting is very possible if proper means of picking and harvesting are not adopted. Therefore, large quantity of tuber and root crops like potato, sweet potato, etc. becomes damage and unmarketable due to faulty methods of digging them out. In fruits like apples, it have soft outer skin which are highly prone to mechanical damage. Therefore, fruits damaged are also prone to pathological attacks like rotting [2,11]. Gradually the quality of fruits deteriorates and the produce fetch lesser prices in the market. The processing operations such as spillage, abrasion, excessive polishing, peeling and trimming add to the loss of commodity. Puncturing of the containers and defective seals also leads to mechanical injury $[2,11]$.

\section{Microbial Action}

Fruits and vegetables are also prone to damage by microbial attack. The microbial spoilage are mainly caused by fungi, bacteria, yeast and moulds. However, a significant portion of losses of fruits and vegetables during post-harvest period is attributed to diseases caused by fungi and bacteria. The succulent nature of fruits and vegetables makes them easily invaded by these organisms [4]. However, apart from attacking fresh fruits and vegetables, these organisms also cause damage to canned and processed products. Many times, serious post-harvest diseases occur rapidly and may cause extensive break down of the commodity, sometimes spoiling the entire package $[2,11]$. It is estimated that $36 \%$ of the vegetable decay is caused by soft rot bacteria. Similarly rot in soft fruits caused by fungi is also very destructive. As far as vegetables are concerned, naturally the source of infection is from the field, water used for cleaning the surface, contact with equipment and storage environment. The most common pathogens causing rots in vegetables and fruits are fungi such as Alternaria, Botrytis, Diplodia, Monilinia, Phomopsis, Rhizopus, Penicillium, Fusarium, etc. Among bacteria Ervinia, Pseudomonas, etc. cause extensive damage. High temperature and relative humidity favour the development of postharvest decay organisms. While more acidic tissue is generally attacked by fungi, but fruits and vegetables with $\mathrm{pH}$ above 4.5 are mainly attacked by bacteria [6].

\section{Environmental Factors}

The environmental factors such as temperature, humidity, composition and proportion of gases in controlled atmospheric storage play an important role in post-harvest loss of fruits and vegetables. The high temperature and relative humidity favour the growth of micro-organisms which result in serious damage to the produce. High temperature also increases the rate of respiration of fruits and vegetables which subsequently result in the breakdown of the inner tissues. Also, high temperature and relative humidity increase the decaying of fruits and vegetables, while decrease in temperature slow down the rate of microbial attack on different crops especially when it is below $5{ }^{\circ} \mathrm{C}$. Chilling injury which is cause by low but not freezing temperature is mainly observed with tropical and subtropical fruits and vegetables. However, the symptoms cause by chilling injury may not be evident while the fruits and vegetables are held at chilling temperature but may become visible only when the fruits and vegetables are transferred to room temperature $\left(37^{\circ} \mathrm{C}\right)$.

In the post-harvest environment, the role play by Relative Humidity (RH) is important as temperature. The effects of temperature and relative humidity are mainly comparable and interrelated because the capacity of air to hold moisture varies with the temperature. The aeration in the storage containers or in stores has its bearing on $\mathrm{RH}$ and hence indirectly on disease development. The effects of high RH on decay is also closely related with the effects of temperature and, for many fruits and vegetables, relative humidity near saturation results in lower decay losses only 
if the temperature is near $0^{\circ} \mathrm{C}$. The relative humidity below $90 \%$ does not however, permit micro-organisms to grow on the surface of fruits and vegetables [12].

Therefore, all fruit and vegetable have their own specific heat requirement during processing. Excessive or insufficient heat supply during processing, improper cold storage temperature and un- desirable gaseous composition of controlled atmosphere of storage lead to physical damage due to tissue break down [13].

\section{Secondary Causes}

Inadequate methods in harvesting, transportation, storage and marketing facilities and legislation result in favourable conditions for causes of secondary causes of loss. Also, inadequate harvesting equipments and rough handling during harvesting results in bruising and increase possibilities of contact of the produce with the soil which may leads to contamination with micro-organisms [11]. Also extended time taken for harvesting and grading in field exposes the fruits and vegetables with field heat for longer period of time which, may subsequently causes faster senescence and reduce shelf life. In addition, the use of improper machinery and equipment's in mechanical harvesting cause serious losses. For example, mechanical harvesting of tomato has been reported to result in more cracking (33\%) than hand picking (10\%). While harvesting of fruits and vegetables during rain or immediately after rains creates conditions favourable for decay organisms. But harvesting during hotter part of the day results in faster senescence, shrivelling and wilting of fruits and vegetables as compared to produce harvested in the early morning or later afternoon [11].

Furthermore, inadequate storage facilities at the producing or marketing centers, exposes the produce to the natural causes of losses ie. damage by micro-organisms, respiration, transpiration and other biochemical reactions. While proper storage, however, creates conditions unfavourable to these factors. Therefore, transportation and distribution of fruits and vegetables are the important stage of post-harvest loss. The physical and mechanical damage occur during transportation and distribution. Longer shipment and distribution period eventually caused heavy losses $[2,7]$. The earlier the harvested produce is consumed, the minimum is the loss, as the period of senescence and organism invasion, multiplication and damage is shortened. This can only be achieved by a well plan set up marketing system.

Therefore, the presence or absence of correct legal standards can affect the eventual retention or rejection of a vegetable or fruit for human consumption. But legal standards vary from country to country and are influenced by the economic status of the population and pressure of the population on the fruit or vegetable consumption. So strict legal standards will give better prices to farmers and superior quality to the consumers.

\section{Control of Post-Harvest Loss}

The magnitude of post-harvest loss in fruits and vegetables can be reduce by proper cultural operations, harvesting, transportation, storage and pre and post- harvest treatments. These are briefly discussed here.

\section{Cultural Operations}

In order to ensure normal development and increase shelf life of fruits and vegetables a good cultural operation is desirable. In perishable, preparation of the soil to a fine tilth of porous nature is necessary to avoid root forking especially for vegetables like root crops such as carrot and radish. Maintenance of regular irrigation during the stage of development of fruits vegetables, bulbs, tubers is of significant importance [13]. Inadequate water supply causes cracking of carrot, radish, tomato and splitting of outer scales of onions. However, excessive and heavy irrigation especially at late maturity after a long dry spell, causes cracking of tomatoes and water- melon. Such perishables have reduced shelf life and poor appeal. In order to ensure better keeping quality for onion and garlic, irrigation should be stopped three weeks before harvesting $[6,13]$.

Faster tissue deterioration in fruits and vegetables is normally encountered when there is heavy application of nitrogenous fertilizers, but normal supply of potassium fertilizers improves the keeping quality of fruits and vegetables [12]. Molybdenum and boron deficiency in some fruits and vegetables such as cabbage and almond results in physiological disorders like greening of almond and heart rot of cabbage. While deficiency of manganese in pea results in marsh spots. Such fruits normally have very poor shelf life and may have marked quality deterioration. It is therefore, advisable to fulfil the optimum need of these micro-nutrients at the right time.

Proper control of weed in orchards and vegetable fields improved the supply of water, nutrients, sunlight and also improve the normal development of fruits and vegetables. Proper training and pruning of fruit trees and removal of dead or infected branches enable the, trees to receive proper sunlight which is essential for the colour and size development of the fruits. In vegetables however, mulching should be adopted as it help to conserves water, nutrients and have control over weeds and helps to obtain quality commodities [12]. Apart from, mulching which disrupt the reflection of soil heat in addition the produce has an extended keeping quality. Staking in pea, tomato and other vine crops are useful in avoiding the contact of vegetables with soil and thereby reduces decay. Blanching and other important operations of cauliflower gives quality curd which store longer period in storage. While destruction cause by birds in orchards can be reduce by using some mechanical devices in addition to good and careful supervision. Sound by beating drum, installing bird-scarers over trees are some measures of reducing damage of fruits by birds [13].

\section{Harvesting and Field Handling}

Studies by Hayatu [7] showed that consumers always prefer fresh, properly matured, insect and disease free fruits and vegetables of attractive appearance. Therefore, vegetables should be harvested as and when they attain good and maximum size and yet are tender. While over maturity in root crops like carrot and radish results in pithiness and sponginess and therefore, their harvesting should not be delayed. However, the delayed harvesting in onion and garlic reduces their shelf life. But almost 
all the crops are badly affected due to delayed harvesting. In case of fruits, ripening in trees is mostly prefer- red. Majority of the fruits are harvested at proper maturity stage but quite earlier than the ripening stage. They, therefore, ripened artificially later on as per the market demands [6].

The best time for harvesting of fruits and vegetables is cooler parts of the day and after harvest the produce should immediately be shifted to the packing shade. But harvesting during hot period of the day normally raises the field heat of the produce and courses wilting and shrivelling. While during or immediately after rains harvesting of vegetables should not be carried out as it creates conditions which favour the multiplication of microorganisms. In developing countries like Nigeria, manual harvesting using spade clippers and knife for fruit picking is still in vogue [2]. Therefore, during harvesting of vegetables, care should be taken to avoid mechanical damage. But for large scale harvesting of tuber crops such as potato or the underground vegetables, the use of mechanical diggers like potato digger is recommended. While during harvesting of fruit harvesting, a quite number of harvesting aids have been developed which discourage the use of ladders, for ego mobile platforms, this place the picker in the correct harvesting position. However, the large size of fruit trees poses a great problem in manual harvesting, resulting in greater damage to the harvested fruits. Yet manual harvesting is easier and more efficient in the case of high density fruits [2,7].

Equipments are like buckets, sacks, baskets and boxes are use in collection of harvested produce from the field to a collection point, but most of these containers are unhealthy and poorly designed, inadequately maintained and unsuitable for the harvesting and transportation of the fresh produce. Therefore, in order to ensure good quality, produce the container for collection of harvested produce should be designed in such a way that they do not cause any injury to the field operations; also a high standard of field hygiene should be maintained. Likewise, produce unfit for the market should be sorted out. Therefore, fruits and vegetables should not be allowed to remain on the ground for any extended period of time as it becomes a source of infection. All the disease infected material should be completely disinfected or destroyed [6].

\section{Washing and Grading}

Fruits and vegetables need good handling before they are packed for transportation. Produce such as root and tuber crops are often washed to remove the soils adhering over them. Fruits and vegetables which have been treated with poisonous chemicals require very good washing before they are pack. Washing with clean water prevent wilting and also improves the appearance of fruits and vegetables [2,7]. In addition, it is important to trimmed vegetables such as cabbage, spinach and lettuce before they are harvested for the market $[2,7]$.

Therefore, for good and effective marketing strategies grading is an important component which should not be neglected. The produce is therefore, sorted into various grades and attractive forms which will attract good price for the produce [2,7]. Sometimes fruits and vegetables are graded on the basis of shape, size and colour. While fruits and vegetables such as okra, cucumber, ridge gourd may also be graded on the basis of their maturity, ripeness in mango and tomato fruits and general appearance. Therefore, during sorting of fruits and vegetables, all the characters that influence quality and appearance should be considered [6].

\section{Packaging}

Significant reduction of wastage of fresh fruits and vegetables is recorded as a result good packaging. In addition, good packaging also ensures protection against mechanical damage, undesirable physiological changes and pathological deterioration during storage, transportation and marketing, likewise freshness, succulence and flavour of fruits and vegetables can be maintained for a longer period through good and effective packaging [2,11]. In many developing countries like Nigeria a number of containers like wooden boxes, corrugated fibre board boxes, jute bags, bamboo baskets, earthen pots are the important packaging materials used. In order to effectively increase the shelf life of fruits and vegetables some cheap packaging technique and materials such as polythene films, paper board boxes lined with polyethylene and other materials may be of valuable important. Also, plastic films provide good protection for the vegetables against dry air.

All the packages must be provided with some amount of ventilation in order to prevent the physiological break- down of the produce. If there is impermeability to car- bon dioxide ( $\mathrm{CO} \sim$, oxygen (02) and water vapour inside the package, there may be the development of off-flavour. While packing for transportation, care should also be taken to avoid bruising and damage of fruits [7]. For this purpose, dry grasses or paddy straw can be successfully used between the layers of fruits. However, packaging is a highly innovative technology and newer techniques and material are being added every year, both for fresh vegetables and fruits and also for processed products. Packages can be flexible or rigid, each group having distinct advantages and limitations. An important application of flexible film is in wrapping the produce for low temperature [7]. A mixture of gases can be inserted in film packs that delay post-harvest changes. Tetraking R, a D-shaped cylinder formed from two webs of polystryene and expanded polystyrene material has been recently introduced along with thermo formed pots for aseptic filling. Sterilization is carried out by either using liquid or vapour of Hydrogen peroxide or using ultra violet or gamma radiation.

\section{Pre-Cooling}

Pre-cooling prevents premature ripening and ageing of the fresh produce. Therefore, it is important to remove field heat of the harvested vegetables, especially when the harvesting is done during hot weather. Cooling, therefore, conserves weight of the fresh produce which gives an added advantage during the extended storage period. In fruits like tomato pre-cooling during storage can reduce Physiological loss in of weight from 6 to 2.9 per cent. While in vegetables which deteriorate very fast good cooling can reduce storage losses [10]. Sometimes, stages of ripening and the level of field heat also determines the need of pre-cooling. 
Therefore, effective pre-cooling can be accomplished by (1) by placing the produce in refrigerated trucks with forced humidified air circulation, (2) by placing ice in packages, (3) by placing ice in water and then passing through a spray of cool water (4) by passing through vacuum cooling. While hydro-cooling, can be accomplished by flooding the field, because water is a good material for transfer the heat from the produce to the cooling medium spraying or immersing, is therefore, a faster and affective control method. Also, a small amount of relevant fungicide can also be added in hydro-cooling water to for the control of fungal growth $[10,11]$. Salad and other leafy vegetables are often cooled by lowering the atmospheric pressure in hermetically sealed chamber until the reduced vaporizing point of water produced at low pressure in the cooling chamber cool the produce. In leafy vegetables and some fruits like grapes are usually very difficult to cool with water or air, but they can be field packed and cooled rapidly and uniformly by vacuum cooling $[10,11]$.

\section{Transportation}

In Nigeria, the transportation of perishable commodities is in the most precarious stage [2]. In our local markets in Nigeria, the produce are brought either by trolley, bus, motorcycles, or tricycle. The long distance of transportation is mainly by rails and trucks, which is very costly. However, the main reason for preference to road transportation against rail or truck is because it takes short transit period. For successful marketing and maintenance of good quality quick transport of fruits and vegetable is important. Most of the losses which occur during transportation occur due to physical and mechanical injury and uncontrolled conditions, mainly temperature and humidity [6]. Therefore, to ensure reduce losses of the produce, adequate long-distance facilities especially by rails should be developed. Also, the produce should be properly packed and stacked in healthy and well-ventilated containers. Control of relative humidity and refrigeration in containers is of important. In addition, maintenance of good roads is recommended for smooth transportation with little or no vibration and jerks. Therefore, good and efficient transport system can go a long way, not only in reducing the post-harvest loss of horticultural produce but also will assist in stabilizing the price fluctuations of various commodities available in different markets of the country.

\section{Reducing Moisture Loss}

The prevention of weight loss of fresh produce is one of the major advantage of consumer packaging especially when moisture retentive films are used, particularly for leafy green vegetables and root crops. This result in extended shelf life of packaged produce over non-wrapped produce, especially when marketing from refrigerated display cases. It has been reported that moisture proof cellulose film, reduced the weight loss of tomatoes to one fourth the amount lost by non-wrapped tomatoes [11]. Lettuce packed in polythene or polystyrene, loses fewer weights and may have a longer shelf life than non-packaged lettuce [1]. Regulation of accumulating humidity is more important for the packaged vegetables.

\section{Marketing of Fresh Produce}

A perfect and efficient marketing system is essential to avoid the losses of fruits and vegetables, and it is possible and at a time when the market needs the produce most and also to get a good return for the effort and money spend. However, marketing of fresh perishables presents more problems compared to other durable agricultural products [1]. In most of the developing countries like Nigeria, the interests of producers as well as consumers are very poorly served, the famers gets less return for their effort and money spend while the consumer pays more than what is necessary. However, during the peak of the season when the market is in glut with a particular vegetable or fruit a lot of wastage or loss is experienced. Also, prices are considerably very low, and farmers get discourage and dejected. Therefore, effort should be made to avoid glutting and the loss should be reduced to the bearest minimum $[1,2,6]$.

\section{Storage at Low Temperature}

The main objective of storage is to extend the shelf life of fruits and vegetables and increase their period of availability. Therefore, a substantial quantity of fruits goes waste in Nigeria and other developing countries due to lack of proper storage facilities $[7,12]$. It should, therefore, be noted that fresh produce are living entities and even after harvest they carry out all the vital physiological activities. Therefore, the primary purpose of storage is to control the rate of respiration, transpiration, ripening and also any un-desirable bio-chemical changes and disease infection. To a greater extent by controlling the post-harvest environmental conditions of temperature, relative humidity and atmospheric concentration of certain gases loss of many fruits and vegetables can be prevented [12].

\section{Refrigeration}

The principle of refrigeration is to bring cool and take out heat from the produce. In mechanical refrigeration, the refrigerated gas for example ammonia takes out the heat from the chamber or store as it expands. Therefore, the expanded gas is then compressed to remove the heat from the compressed air over the tubes containing the hot gases. The gas is liquefied, and the cycle is then repeated. Therefore, fruits and vegetables can be safely kept for a long period through refrigeration [12].

\section{Cold Storage}

Alao [2] reported that the most suitable condition for fresh fruits and vegetables in storage is the lowest temperature, which does not cause chilling injury to the fresh produce. Any variation from the desired condition is detrimental. Relative humidity of the store rooms also has a considerable bearing on the keeping quality of the fresh produce. Therefore, control of moisture in air is very difficult [12]. The rate of respiration has direct correlation with temperature, as the temperature is high more will be the rate of respiration and multiplication of decay organisms. But it should be noted that the temperature and relative humidity requirements differ for different fruits and vegetables. Therefore, the maximum cold storage conditions for fruits and vegetables are given separately in Tables 1 \& 2 [6]. 
Table 1: Recommended storage temperature and relative humidity for different fruits.

\begin{tabular}{|c|c|c|c|c|}
\hline Sl.No & Name of the fruit & Storage temp.(\%) & Relative humidity(\%) & Storage period (weeks) \\
\hline 1 & Pineapple & $8-10$ & $85-90$ & $1-2$ \\
\hline 2 & Pomegranate & $0-1.66$ & $85-90$ & $16-17$ \\
\hline 3 & Guava & $8.30-10.00$ & $80-85$ & 4 \\
\hline 4 & Mango & $7.20-8.80$ & $85-90$ & $4-7$ \\
\hline 5 & Emblica (amla) & $0-1.66$ & $85-90$ & $7-8$ \\
\hline 6 & Grapes & $0-1.66$ & $80-85$ & $6-8$ \\
\hline \multirow[t]{3}{*}{7} & Fig & & & \\
\hline & (a) Fresh fruits & $0-1.66$ & $80-90$ & 4 \\
\hline & (b) Dried fruits & $0-1.66$ & $65-70$ & 52 \\
\hline 8 & Cashewnut & $0-1.66$ & $85-90$ & $4-5$ \\
\hline 9 & Jackfruit & $11.10-12.70$ & $85-90$ & 6 \\
\hline \multirow[t]{3}{*}{10} & Banana & & & \\
\hline & (a) For ripening & $15.50-21.00$ & $80-85$ & $1-2$ \\
\hline & (b) Ripened fruit & $11.10-12.70$ & $85-90$ & 3 \\
\hline \multirow[t]{3}{*}{11} & Date palm & & & \\
\hline & (a) Fresh fruits & $7.2-8.80$ & $85-90$ & 2 \\
\hline & (b) Dried fruits & $0-1.66$ & $65-70$ & $40-52$ \\
\hline 12 & Grapefruits & $7.20-8.80$ & $85-90$ & 12 \\
\hline 13 & Roughlime & $5.50-7.20$ & $85-90$ & $13-17$ \\
\hline 14 & Sapota (cheeku) & $1.66-3.30$ & $85-90$ & $6-8$ \\
\hline 15 & Cherry & $0-1.66$ & $85-90$ & 2 \\
\hline 16 & Pear & $0-1$ & $85-90$ & $13-26$ \\
\hline 17 & Papaya & $8.30-10.00$ & $80-85$ & $1-2$ \\
\hline 18 & Passion fruit & $5.50-7.20$ & $80-85$ & $4-5$ \\
\hline \multirow[t]{6}{*}{19} & Malta & & & \\
\hline & (a) Malta common & $3.90-5.50$ & $85-90$ & 17 \\
\hline & (b) Blood Red & $2.20-3.90$ & $85-90$ & 17 \\
\hline & (C) Mosambi & $5.50-7.20$ & $85-90$ & 21 \\
\hline & (d) Valentia late & $3.90-5.50$ & $85-90$ & 17 \\
\hline & (e) Sathgudi & $5.50-7.20$ & $85-90$ & 17 \\
\hline 20 & Lime & $8.30-10.00$ & $85-90$ & $6-8$ \\
\hline 21 & Litchi & $0-1.66$ & $85-90$ & 10 \\
\hline 22 & Lemon & $7.20-8.80$ & $85-90$ & $8-12$ \\
\hline 23 & Strawberry & $0-1.66$ & $85-90$ & $5-6$ \\
\hline 24 & Santara & $3.90-5.50$ & $85-90$ & $10-14$ \\
\hline 25 & Apple & $0-1.66$ & $85-90$ & $17-34$ \\
\hline 26 & Plum & $0-1.66$ & $85-90$ & $2-4$ \\
\hline 27 & Peach & $0-1.66$ & $85-90$ & 2 \\
\hline 28 & Bael & $8-9$ & $85-90$ & $10-12$ \\
\hline
\end{tabular}


Table 2: Recommended storage temperature and relative humidity for different vegetables.

\begin{tabular}{|c|c|c|c|c|}
\hline SI.No & Name of vegetable & Temperature $(0 \mathrm{C})$ & Relative humidity (\%) & Storage life (weeks) \\
\hline 1 & Asparagus & $0-0$ & 95 & $3-5$ \\
\hline 2 & Brinjal & $10.0-11.10$ & 92 & $2-3$ \\
\hline 3 & Dolichos lablab (pod) & $0.0-1.7$ & 90 & 3 \\
\hline 4 & Beet (topped) & $0.0-1.7$ & $90-95$ & $8-14$ \\
\hline 5 & Beet (bunched) & 0.0 & 90 & 1.5 \\
\hline 6 & Bitter gourd & $0.6-1.7$ & $85-90$ & 4 \\
\hline 7 & Cabbage (early) & $0.0-1.7$ & $92-95$ & $4-6$ \\
\hline 8 & Cabbage (late) & $0.0-1.7$ & $92-95$ & 12 \\
\hline 9 & Carrot (topped) & 0.0 & 95 & $20-24$ \\
\hline 10 & Cauliflower & $0.0-1.7$ & $85-95$ & 7 \\
\hline 11 & Celery & $0.6-0.0$ & $92-95$ & 8 \\
\hline 12 & Colocasia & $11.1-12.8$ & $85-90$ & 21 \\
\hline 13 & Coriander & $0.0-1.7$ & 90 & 5 \\
\hline 14 & Cucumber & $10-11.7$ & 92 & 2 \\
\hline 15 & Garlic & 0.0 & 65 & $28-36$ \\
\hline 16 & Ginger & $7.2-10.0$ & 75 & $16-24$ \\
\hline 17 & Lettuce (head) & 0.0 & $90-95$ & 3 \\
\hline 18 & Lettuce (leaf) & 0.0 & 95 & 1 \\
\hline 19 & Limabean (pod) & $4.4-7.2$ & $90-95$ & $1.5-2$ \\
\hline \multirow[t]{3}{*}{20} & Muskmelon & & & \\
\hline & (a) Cantaloupe & $1.7-3.3$ & $85-90$ & 1.5 \\
\hline & (b) Honey dew & 7.2 & 85 & 4.5 \\
\hline 21 & Okra & 8.9 & 90 & 2 \\
\hline 22 & Onion (leaf) & 0.0 & $90-95$ & 2 \\
\hline 23 & Onion (bulbs) & 0.0 & $70-75$ & $20-24$ \\
\hline 24 & Pea (green) & 0.0 & $88-92$ & $2-3$ \\
\hline 25 & Pepper (ripe) & $5.6-7.2$ & $90-95$ & 2 \\
\hline 26 & Potato (Irish) & $3.0-4.4$ & 85 & 34 \\
\hline 27 & Pumpkin & $1.7-11.6$ & $70-75$ & $24-36$ \\
\hline 28 & Radish (topped) & 0.0 & $88-92$ & $3-5$ \\
\hline 29 & Squash (winter) & $12.8-15.6$ & $70-75$ & $24-36$ \\
\hline 30 & Sweet potato & $10-12.8$ & $80-90$ & $13-20$ \\
\hline 31 & Cassava & $0-1.7$ & 85 & 23 \\
\hline 32 & Tomato (unripe) & $8.9-10.0$ & $85-90$ & $4-5$ \\
\hline 33 & Tomato (ripe) & 7.2 & 90 & 1 \\
\hline 34 & Turnip & 0.0 & $90-95$ & $8-16$ \\
\hline 35 & Watermelon & $7.2-15.6$ & $80-90$ & 2 \\
\hline
\end{tabular}

According to Williams et al. [11] one of the most important contribution to the storage technology is the Controlled Atmosphere (CA) storage, were low level of Oxygen $\left(\mathrm{O}_{2}\right)$ and high level of Carbon Dioxide $\left(\mathrm{CO}_{2}\right)$ and are maintained. The controlled atmosphere storage when combined with refrigeration, it result in retardation of the respiratory processes and this have the capacity to delay yellowing, softening, quality changes, and other deteriorative processes. Nevertheless, the significant factor in storage under CA is the adherence or susceptibility of the fruits and vegetables to the damage which result from reduced concentration of $\mathrm{O}_{2}$ and increased $\mathrm{CO}_{2}$. Therefore, the tolerance of individual produce differs considerably and is mainly dependent on morphology, age, temperature, and anatomy of the produce. The first step in controlled atmosphere is a gas-tight envelope around the produce while the second step is maintaining the concentration of $\mathrm{O}_{2}$ and $\mathrm{CO}_{2}$ at a preferred concentration $[6,11]$.

The beneficial derived from CA storage are

(i) By regulating the process of respiration and senescence shelf life of perishables would be extended. 


\section{(ii) Ethylene sensitivity reduction, and}

(iii) Reduction in the incidence of disease-causing pathogens like bacteria, fungi, insects pests, in fresh produce. Williams et al. [11] report showed that storage under CA was found to be effective for fruits and vegetables which rapidly deteriorate and those were ripening is complete after harvest [11].

Even though storage under CA storage has been found to be very effective in increasing shelf life of fresh produce yet it can also cause adverse effects like

(i) Increasing physiological disorders,

(ii) Irregular ripening,

(iii) Off-flavour of produce

(iv) Concentration of organic acids.

\section{Ionizing Radiation}

The most important advantages of the ionizing radiation is that it can destroy the pathogenic organisms without appreciably raising the temperature of the produce. Though it involves high initial capital involvement $[4,11]$. The Pasteurization with ionizing radiations (radurization) has being widely accepted because of its easy application, it leaves no residue and require minimal energy expenditure. The ionizing radiation prolong the shelf life of perishables as surface pasteurization, sprout inhibition and slowing the process of senescence. Irradiation with 25-35 krads is found to be effective in delaying the initiation of natural ripening of banana without interfering with affecting the quality of the fruit. The ionizing radiation also prevents the sprouting of potatoes, onions and other bulbs most effectively at. 10-15 krads.

\section{Waxing}

The main importance of wax coating is to reduce evaporation and respiration [2]. Also, where refrigerated storage facilities are not available or are in adequate, protective skin coating with wax is one of the methods use for increasing the shelf life of fresh produce $[4,12,13]$. Fruits and vegetables passed through the water emulsified with mustard oil increase the shelf life of many fruits and vegetables such as tomato, okra, mangoes, etc.

\section{Chemical Treatment}

Apart from fungicides there are a number of chemicals which increase the storage life of fruits and vegetables by delaying the process of ripening and senescence. Post-harvest treatment with gibberellic acid markedly delayed the ripening of banana $[4,7]$. Potassium per magnate is used as an ethylene absorbent to keep the ethylene below the threshold level. The maleic hydrazide has been found to be very effective on the on the ripening process of different fruits. At 1000-2000 ppm (parts per I million) maleic hydrazide delays the ripening of mangoes [1,9].

The application of post-harvest plant hormones has been found to extend the shelf life of vegetables. While the effect of cytokinin is conspicuous, especially in leafy vegetables, but post-harvest application of gibberelins slow down the ripening of tomato [7].
Application of Indole Acetic Acid (1AA) solution helps to maintain the green colour of pods of many vegetables. However, application of 2,4-D when combined with BA (M6-benzyladenine), will retard the yellowing of cauliflower and some other green vegetables. Also sprays of Maleic Hydrazide ( $\mathrm{MH}$ ) before harvest inhibit sprouting of onion and potato in storage $[6,9]$.

\section{Effect of in-Package Desiccants}

For maintenance of the succulent and tenderness of fruits and vegetables, partial dehydration is carried out and thereafter inpackage desiccants are used to lower the level of moisture. The use of in- package desiccants like calcium oxide or fumed silicas, help to bring the moisture content of the storage environment to I \% or lower, this allows the increase in shelf life of dehydrated fruits and vegetables [4].

\section{Importance of Fungicides}

The control of pathogenic micro-organism causing losses of fresh produce requires the use of fungicides, in addition to several modification of techniques of cultivation and the development of resistant or tolerant varieties. Pre-harvest spraying of fungicides can result in significant reduction of the pathogens in the harvested produce. The best method of application of fungicides and antibiotics is to mix them in wax emulsions [2,7]. Sulphur Dioxide $\left(\mathrm{SO}_{2}\right)$ use in fumigation of stored materials help to prevent the spread of fungi like Botrytis. While other fumigants like bi-phenyl acetaldehyde, propylene oxide, ethylene oxide, nitrogen trichloride can also be used. Dipping in 1000 ppm streptomycin (50-500 ppm) can prevent bacterial soft rot of packed spinach and lettuce. It also marked inhibit the activity of a number of micro-organisms and extend the shelf life and added nutritive value to foods [4].

However, it is recommended that the post-harvest treatment of fruits and vegetables with poisonous chemicals should be avoided. In situations where it became necessary, the consumption of such fruits and vegetables should be delayed for at least one or two months as they may create health hazard most especially different respiratory and digestive disorders after consumption [1,2,7].

\section{Conclusion}

Post-harvest loss of fruits and vegetables occur due to lack of proper technique of harvesting, transportation, storage and distribution. The freshness of fruits and vegetables after harvest is controlled by water content, respiratory rate, ethylene production, endogenous plant hormones and exogenous factors such as microbial growth, temperature, relative humidity and atmospheric compositions. Therefore, post-harvest loss of fruits and vegetables can be considerably reduced and their shelf life increased by careful manipulation of these factors. The loss can be reduced by implementing the important cultural methods, careful handling and packaging. The use of appropriate chemicals at pre and postharvest stage may prolong the availability of fresh produce for a long period of time by protecting them from pathogens and other environmental factors. Also controlled atmosphere storage and redurization at low temperature has been found to be effective for fruits and vegetables. 


\section{References}

1. Yahaya SM, Fagwalawa LD, Ali MU, Lawan M, Mahmud S (2015) Isolation and Identification of Pathogenic Fungi Causing Deterioration of Lettuce Plant (Lactuca sativa) A Case Study of Yankaba and Sharada Vegetables Markets. J Plant Sci Res 3(1): 1-4.

2. Alao SE L (2000) The importance of post-harvest loss prevention. Paper presented at graduation ceremony of school of food storage technology. Nigerian Stored Products Research Institute, Kano p. 1-10.

3. Mustapha Y, Yahaya SM (2006) Isolation and Identification of Postharvest fungi of Tomato (L. esculentum) and Pepper (Capsicum annum) sample from selected Irrigated sites in Kano. Biological and Environmental Science Journal for the Tropics 3: 139-141.

4. Elias SN K, Shaw MW, Dewey FM (2010) Persistent symptomless, systemic and seed-borne infection of lettuce by Botrytis cinerea. European Journal of Plant Pathology 126(1): 61-71.

5. (1989) The State of Food and Agricultural. Rome, p. 20-56.

6. Opadokun JS (1987) Reduction of post-harvest losses in fruits and vegetables. Joint National Crop Protection Workshop, IAR, Zaria, p. 3-26.

ISSN: 2574-1241

DOI: $10.26717 / B J S T R .2019 .13 .002448$

Yahaya SM. Biomed J Sci \& Tech Res

(C) This work is licensed under Creative

Submission Link: https://biomedres.us/submit-manuscript.php
7. Hayatu M (2000) Post-Harvest physiological studies of some selected members of family Solanaceae. Kano, p. 2-25.

8. Sani MY, Alao SE L (2006) Assessment of Post-harvest fungi of Tomato and Pepper in selected Irrigation areas of Kano State. Nigeria International Journal of Research in Bioscience p. 53-56.

9. Food and Agricultural Organization (2011) FAO Statistical-Database. Rome, Italy.

10. Williams CN, Uzo JO, Peregrine WT (1991) Vegetables Production in the Tropics. Longman, England, pp. 179.

11. Yahaya SM (2005) Contribution of harvest to pathogenic and nonpathogenic losses of vegetables grown in Kano State- Nigeria. Bayero University, Kano.

12. Danladi DK (2000) Nigeria agriculture: The efficiency factor announce this article to your friends. p. 1-3.

13. Cho J (2008) Winter diseases of lettuce. University of Hawaii, Commodity fact sheet, Institute of Tropical Agriculture and Human Resource.

\begin{tabular}{ll} 
BIOMEDICAL & Assets of Publishing with us \\
RESEARCHES & - Global archiving of articles \\
\hline ISSN: 2574-1241 & - Immediate, unrestricted online access \\
\hline
\end{tabular}

